\title{
A diary study on shared leadership, team work engagement, and goal attainment
}

\author{
Kai N. Klasmeier*1 \\ Jens Rowold ${ }^{2}$
}

${ }^{1}$ Federal Institute for Occupational Safety and Health (BAuA), Dortmund, Germany

${ }^{2}$ Center for Higher Education, TU Dortmund University, Dortmund, Germany

* Kai N. Klasmeier, Federal Institute for Occupational Safety and Health, Friedrich-Henkel-Weg

1-25, 44149 Dortmund, Germany, klasmeier.kai@baua.bund.de

This is a post-print version which may not exactly replicate the final version published in the journal. The final peer-reviewed and edited copy of this manuscript is freely accessible via the website of the Journal of Occupational and Organizational Psychology:

https://doi.org/10.1111/joop.12371

Acknowledgments: The authors would like to thank Astrid Emmerich, Birgit Thomson, Jana Fürchtenicht, and Joachim Hüffmeier for providing feedback on earlier drafts of this article. 


\begin{abstract}
Theory of shared leadership has suggested that this informal source of team leadership is highly dynamic and changes over time. We draw on this assumption and provide new insights about the nature of short-term changes in shared leadership. Additionally, we advance the nomological network of shared leadership by examining the within-team relations of day-level shared leadership with cohesion, team work engagement and goal attainment. To study these dynamics and short-term relationships, we conducted a daily-diary study. We collected daily measures from 53 teams with 187 team members resulting in 725 person-days and 207 team-days. Bayesian multilevel modeling supported our hypotheses as daily shared leadership was linked to daily cohesion, team work engagement, and goal attainment. The findings contribute to the understanding of within-team associations of shared leadership and add to the understanding about the dynamic nature of this team state. Limitations and directions for further research are then discussed.
\end{abstract}

Keywords: shared leadership; team work engagement; daily-diary study; multilevel modeling; Bayesian analysis 


\section{A diary study on shared leadership, team work engagement, and goal attainment}

In the past decades, collective forms of leadership and their influence on team processes and performance have received increased attention by scholars and practitioners (e.g., Contractor, DeChurch, Carson, Carter, \& Keegan, 2012; Pearce, 2004). In regard to this, scholars defined shared leadership as an emergent team property that results from the distribution of leadership influence across the team members (Carson, Tesluk, \& Marrone, 2007). Previous research highlighted the role of shared leadership as an important driver of team effectiveness over and above the influence of vertical leadership (Nicolaides et al., 2014; D. Wang, Waldman, \& Zhang, 2014). However, shared leadership has mostly been considered from a between-team or static perspective due to cross-sectional designs. This may result in a limited understanding of shared leadership as it has been conceptualized as a dynamic ${ }^{1}$ state (e.g., D'Innocenzo, Mathieu, \& Kukenberger, 2016; Pearce \& Conger, 2003; Zhu, Liao, Yam, \& Johnson, 2018). For example, as teams are faced with new tasks or unclear situations, they may alter their shared leadership behavior to deal with these changes. In general, leadership behavior is likely to vary over time (i.e., is subject to short-term temporal changes or fluctuations). Following a recent review, about $50 \%$ of the variation in leadership behavior may be due to changes and fluctuations over time (Kelemen, Matthews, \& Breevaart, 2020). As shared leadership is one specific form of team leadership (Morgeson, DeRue, \& Karam, 2010), it is highly probable that shared leadership is also subject to within-team variations over time. Hence, this study aims to advance theory of

${ }^{1}$ In principle, temporal dynamics refer to short- and long-term changes (e.g., McClean, Barnes, Courtright, \& Johnson, 2019). Whereas long-term dynamics in shared leadership have been studied against the background of team life-cycle models and team development literature (see Drescher, Korsgaard, Welpe, Picot, \& Wigand, 2014), our study focus is about unsystematic day-level fluctuations or short-term changes. Accordingly, the term dynamics refers to short-term dynamics in this study. 
shared leadership with insights about the nature of its short-term changes. This knowledge may provide a new perspective on short-term shaping of team states and team behavior, as an alternative approach besides focusing on long-term team development or stable team characteristics (cf. Humphrey \& Aime, 2014; Kozlowski \& Chao, 2018). To investigate withinteam variations of shared leadership, we conducted a daily-diary study with teams (cf. Ohly, Sonnentag, Niessen, \& Zapf, 2010; Kelemen et al., 2020).

Additionally, little is known about how short-term temporal changes (i.e., daily fluctuations) in shared leadership behavior are associated with team outcomes (Kozlowski, Mak, \& Chao, 2016). As diary studies offer the opportunity to investigate phenomena more immediately (e.g., Gabriel et al., 2018; Kelemen et al., 2020), it may be beneficial to consider more proximal outcomes of shared leadership rather than broader conceptualizations of shared leadership outcomes (see D. Wang et al., 2014). Pearce and Conger (2003) pointed out that attaining collective goals is a central aim of shared leadership. To advance the nomological network of shared leadership and to get a more nuanced view on its within-team relationships (cf. Kelemen et al., 2020), it may be useful to examine in how far the daily fluctuations in shared leadership are related to day-level progress in attaining collective goals. Moreover, by simultaneously considering the within- and between-team relations of shared leadership from a multilevel perspective, this study accounts for possible endogeneity bias for the within-team relationships due to between-team differences (Antonakis, Bastardoz, \& Rönkkö, 2019). This means that the within-team results are independent from any stable between-team differences (e.g., average level of the focal constructs) or omitted causes on the team-level (e.g., team diversity, team member personality). 
While goal attainment refers to a more task- and performance-related aspect of team outcomes, it is also important to consider motivational and well-being related aspects of team outcomes as this may contribute to a more comprehensive examination of the nomological network of shared leadership. In doing so, we draw on recent theoretical considerations of work engagement that shift from an individual to a collective perspective. Costa, Passos, and Bakker (2014b, p. 418) defined team work engagement as a shared, positive and fulfilling, motivational emergent state of work-related well-being that is influenced by team processes and other emergent states. In general, research regarding the motivational potential of shared leadership is scarce (Aubé, Rousseau, \& Brunelle, 2018). Accordingly, it is still unclear how the team members experience shared leadership and in how far shared leadership can contribute to a shared experience of collective engagement. As shared leadership can make the collective work more stimulating and fulfilling (see Aubé et al., 2018), we assume that shared leadership is positively related to team work engagement. Moreover, team work engagement is theoretically expected to fluctuate over time (Costa, Passos, \& Bakker, 2014b) which highlights the importance of our purpose studying possible consequences of short-term changes in shared leadership. Therefore, this study generates insights to extend the nomological network of shared leadership and can answer the question whether shared leadership can contribute to a shared experience of collective engagement on the day-level (i.e., within teams). Additionally, we add to the literature about team work engagement by highlighting its relation to shared leadership.

Besides the relation with team work engagement and goal attainment, we consider cohesion as further outcome of day-level shared leadership. Cohesion has also been conceptualized as a dynamic team state (Kozlowski \& Chao, 2012) and has been associated with shared leadership in past studies, however without a focus on short-term dynamics (see Bergman, 
Rentsch, Small, Davenport, \& Bergman, 2012; Mathieu, Kukenberger, D'Innocenzo, \& Reilly, 2015). Moreover, as cohesion has been linked to several team outcomes (e.g., team work engagement, Rodríguez-Sánchez, Devloo, Rico, Salanova, \& Anseel, 2017; and team effectiveness, Castaño, Watts, \& Tekleab, 2013), it is important to study whether shared leadership is related to team work engagement and goal attainment over and above the influence of cohesion. This can help to provide conceptual clarity and to establish shared leadership as an important team state that has unique contributions to team outcomes. Additionally, as cohesion is likely related to shared leadership as well as team work engagement and goal attainment, it may be a confound for the relations of shared leadership with these outcomes. Relatedly, short-term fluctuations in cohesion may reflect other day-specific confounds within the team (e.g., social exchange processes, conflicts, team affective tone, see Kozlowski \& Chao, 2012). Thus, we further include cohesion as outcome of shared leadership and additionally as control variable. In summary, our study makes several contributions to the current team literature. We provide new insights about short-term changes and fluctuations of team emergent states and team behavior by conducting one of the first daily diary studies with teams. Especially, we focus on shared leadership and illuminate how shared leadership in teams fluctuates from day-to-day. In doing so, we provide a test of theory about the dynamic nature of this team state. Moreover, we expand the nomological network of shared leadership and provide new insights about its daylevel relations with short-term changes in cohesion, team work engagement, and goal attainment. In this way, we also add to the literature about team work engagement (Costa et al., 2014b) and highlight informal team leadership as a possible day-level antecedent. 


\section{A theoretical framework of shared leadership}

Over the years, scholars have drawn on different definitions and conceptualizations of shared leadership. In a recent review, Zhu et al. (2018) outlined three key characteristics of shared leadership, which are common for its conceptualization: 1) shared leadership is lateral influence among peers, 2) shared leadership is an emergent team property, and 3) leadership roles and influence are dispersed across team members (Zhu et al., 2018). The first characteristic refers to the source of leadership influence (Zhu et al., 2018), and distinguishes shared leadership from traditional top-down oriented leadership approaches that are mainly focused on the influence of a formally assigned individual (i.e., team leader, Morgeson et al., 2010). Following this rationale, shared leadership is an informal and internal source of leadership influence within teams (Morgeson, DeRue, \& Karam, 2010). The second characteristic puts the focus on the unit of analysis, as shared leadership is viewed as a team-level emergent state (Zhu et al., 2018). An emergent state "originates in the cognition, affect, behaviors, or other characteristics of individuals, is amplified by their interactions, and manifests as a higher-level, collective phenomenon" (Kozlowski \& Klein, 2000, p. 55). This definition highlights the multilevel structure, the processual mechanisms, and the temporal dynamics of emergent states (Kozlowski, 2015). The third characteristic refers to the distribution of leadership influence within a team. As leadership is not solely located in a single individual, it emerges from mutual claims and grants of leadership influence among the team members (DeRue \& Ashford, 2010; Zhu et al., 2018).

According to Kozlowski and colleagues (2013), emergent states are highly dynamic and change over time. Although, theoretical considerations of shared leadership highlight its dynamic nature (e.g., Pearce \& Conger, 2003), past research lacks a short-term perspective that captures fluctuations and dynamics of shared leadership. Neither are there studies available dealing with 
shared leadership on a daily level, even though within-team changes of shared leadership from one day to another seem to be highly likely (see relatedly, Kozlowski, 2015; Kozlowski et al., 2016). These changes can occur due to different aspects of the team setting (e.g., day-specific behavior of the formal team leader, high work pressure, or changes in the team task). For example, routine tasks may require less shared leadership than complex tasks, as the challenging demands of complex tasks may cause the team members to engage more in structuring their work or problem solving (cf. Morgeson et al., 2010). Moreover, as assumed by adaptive leadership theory, the perceived risk of claiming or granting a leader role in the team depends on situational features (DeRue \& Ashford, 2010; DeRue, 2011). Unclear situations (e.g., task conflicts or contradictory goals) involve a higher risk for claiming leadership influence and shared leadership may become less likely (DeRue \& Ashford, 2010). In summary, sharing leadership influence and engaging in different leadership functions within the team may vary depending on the team setting, team processes, or task characteristics (cf. Marks, Mathieu, \& Zaccaro, 2001; Morgeson et al., 2010). Besides these situational or task-related aspects, some types of teams may also show more short-term changes in shared leadership. For instance, Lorinkova and Bartol (2021) could show that project teams exhibited varying degrees of shared leadership due to different stages of their project work.

We can also draw conclusions from research on vertical leadership, as shared leadership is a source of team leadership of which the primary function (the satisfaction of a team's needs) is similar to vertical leadership (an assumption of functional leadership approach is to study the source of team leadership and not the leader as a person, McGrath, 1962; Morgeson et al., 2010). Recent studies take a short-term perspective and investigate the impact of vertical leadership on a daily basis (e.g., ethical leadership, Bormann, 2017; or transformational leadership, Kuonath, 
Specht, Kühnel, Pachler, \& Frey, 2017). These studies revealed a high amount of day to day variability in leadership behaviors (Kelemen et al., 2020). For example, Tims, Bakker, and Xanthopoulou (2011) could show that up to $75 \%$ of the variations of transformational leadership can be attributed to daily changes. In summary, within-team changes in shared leadership behaviors are likely, but have not been examined by previous studies. In the present study, we address this issue and examine the consequences of fluctuations of shared leadership in a daily diary study with teams.

\section{Shared leadership and team cohesion}

Following Zaccaro, Rittman, and Marks (2001, p. 466), team cohesion reflects the degree of team members' integration in which the members share strong commitment to one another as well as to the team's purpose. Some previous studies have differentiated between two facets of cohesion: Social cohesion represents the interpersonal attraction and liking of the team members, whereas task cohesion represents the shared commitment to the team goal (Mullen \& Copper, 1994; for a criticism of this differentiation see Tekleab, Quigley, \& Tesluk, 2009). In our study, we focus on the task-related facet of cohesion as this facet seems to be most relevant for shared leadership (which is leading towards common goals; Pearce \& Conger, 2003).

Recent theory-building highlights the dynamic nature of team cohesion (Kozlowski \& Chao, 2012). Accordingly, we assume that daily changes in cohesion are related to day-level shared leadership. On days with higher levels of shared leadership, team members show more mutual influence behavior. As this leadership influence is directed towards a common goal, team members experience more day-specific alignment and shared commitment to this goal which may be reflected in higher day-level cohesion. Vice versa, less shared leadership on some days 
may result in disengagement and lower agreement about the team's purpose, and thus lower daylevel cohesion.

From a functional leadership perspective, team members provide feedback, support the social climate and engage in collective problem-solving (Morgeson et al., 2010). In this way they can create a supportive and trustful team environment on days with high levels of shared leadership. Accordingly, the team members feel that they 'stick together' to collaborate effectively as a team and may therefore experience higher day-level cohesion (Bergman et al., 2012; Mathieu et al., 2015). Prior research supports our assumptions: Mathieu et al. (2015) found a positive association between shared leadership and cohesion. Following this rationale, withinteam changes in shared leadership may be related to day-specific fluctuations in team cohesion:

Hypothesis 1: Day-level shared leadership is positively related to day-level team cohesion.

\section{Shared leadership and team work engagement}

Recent theoretical developments shift the focus from an individual perspective of work engagement towards a team-level perspective and conceptualize work engagement as a teamlevel phenomenon. In their theoretical model, Costa and colleagues define team work engagement as a shared, positive and fulfilling, motivational emergent state of work-related wellbeing (Costa et al., 2014b, p. 418). It is important to note that team work engagement is not the sum of individuals' work engagement, but the common observable experience of the team members (i.e., referent-shift consensus model, Chan, 1998; Costa, Passos, \& Bakker, 2014a).

The emergence of team work engagement depends mainly on the team's inputs, processes, and outputs, and is also shaped by other emergent states (Costa et al., 2014b). Following this assumption, team work engagement is likely associated with shared leadership: 
Shared leadership — as a collective influence process within teams — affects proximal outcomes and team processes (e.g., Bergman et al., 2012; Drescher et al., 2014; Mathieu et al., 2015; Zhu et al., 2018). On days when team members show more shared leadership behaviors, they can create a supportive and trustful work environment (Zhu et al., 2018), and this day-specific collective experience is likely to result in a shared motivational state of team work engagement (Costa et al., 2014b). Prior studies regarding team-level work engagement give preliminary support to this rationale (Torrente, Salanova, Llorens, \& Schaufeli, 2012).

Our hypothesis gains further support by taking a closer look at the motivational potential of shared leadership. Striving for collective goals is a central aim of shared leadership (Pearce \& Conger, 2003). Team members mutually lead and influence each other towards their collective goals and the experience of daily progress in this process of collective goal-striving can boost team work engagement (Costa et al., 2014b). Moreover, as leadership responsibilities are shared and the teams execute leadership functions on a given day (e.g., providing feedback or structuring and planning tasks, Morgeson et al., 2010), team members collectively experience above-average autonomy and competence and, thus, develop a higher engagement (cf. Deci, Olafsen, \& Ryan, 2017). Additionally, Aubé, Rousseau, and Brunelle (2018) argued that shared leadership can make the collective work more stimulating. High day-level shared leadership means that the team members not only exhibit more claiming or granting behavior, but also show reciprocal claims and grants of leadership influence on a day (DeRue \& Ashford, 2010). These reciprocal leading-following interactions between the team members may be collectively experienced as optimal functioning of the team, and can contribute to more day-level dedication and absorption towards the collective work (cf. Costa et al., 2014b). There is some support for 
this line of reasoning, as shared leadership has been linked to the experience of flow (Aubé et al., 2018).

Past research has also linked cohesion with team work engagement (Rodríguez-Sánchez et al., 2017) rendering this construct a possible control variable. In highly cohesive teams, the team members show commitment towards the team, experience integration, and have a strong shared purpose (Castaño et al., 2013; Kozlowski \& Chao, 2012). Furthermore, team members may experience the collective work as more supportive and satisfying (Liang, Shih, \& Chiang, 2015; Tekleab et al., 2009). Accordingly, on days with above-average cohesion, the team members are likely to show more dedication and vigor to their work so that high team cohesion may facilitate team work engagement (Costa et al., 2014b). For this reason, we control for cohesion when theorizing about shared leadership as possible day-level antecedent of team work engagement:

Hypothesis 2: Day-level shared leadership is positively related to day-level team work engagement while controlling for day-level team cohesion.

\section{Leading towards collective goals: shared leadership and goal attainment}

Attaining common goals is a crucial purpose for teamwork and team effectiveness (Kozlowski \& Ilgen, 2006; Mathieu, Hollenbeck, van Knippenberg, \& Ilgen, 2017; Mathieu, Maynard, Rapp, \& Gilson, 2008) and also a salient aim of shared leadership (e.g., Pearce \& Conger, 2003). Additionally, theories regarding shared leadership point out that mutual leading-following interactions (e.g. Chiu, Owens, \& Tesluk, 2016; DeRue \& Ashford, 2010) and sharing different leadership functions among the team members (Morgeson et al., 2010) are associated with an increase in team effectiveness. These theoretical assumptions have received numerous empirical evidence from several meta-analyses with a specific emphasis on the 
performance-enhancing potential of shared leadership (D’Innocenzo et al., 2016; Nicolaides et al., 2014; D. Wang et al., 2014), however, without a focus on the day-level.

Daily leading-following interactions can support a more effective use of the team's internal resources, knowledge, and expertise to enhance team effectiveness (cf. Chiu et al., 2016; Day, Gronn, \& Salas, 2004). When teams show more shared leadership on a given day, the team members engage more strongly in claiming and granting leadership influence. This means that team members with high expertise bring in their knowledge and resources by taking a leadership role and the other team members utilize the received leadership influence for the daily task work (see Kukenberger \& D'Innocenzo, 2020). Additionally, day-level leadership influence can be used to solve problems or remove obstacles during the daily work (cf. He et al., 2020), which can also facilitate the process of goal attainment. Hence, daily leadership influence of the team members should result in daily progress in achieving the team objectives.

Besides this, cohesive teams can also concentrate their efforts to achieve common goals (Castaño et al., 2013). Accordingly, high day-level cohesion can enhance day-level goal attainment, as the team members experience a strong commitment towards each other. However, a high day-level shared leadership does not only relate to the experience of being committed to each other and the team's purpose. It also encompasses an active engagement in problem solving or structuring and planning the daily teamwork on a behavioral level (Morgeson et al., 2010). Therefore, we assume that day-level shared leadership is related to goal attainment over and above the influence of day-level cohesion:

Hypothesis 3: Day-level shared leadership is positively related to day-level goal attainment while controlling for day-level team cohesion. 


\section{Method}

\section{Sample and research design}

This study was part of a larger project and some additional data have been collected for the purpose of university teaching. The list of all measured constructs can be requested from the corresponding author. The present study uses an experience sampling design (Gabriel et al., 2018; Ohly et al., 2010) with daily measurement occasions on five consecutive working days. As diary studies with teams are novel, we drew from prior research on vertical leadership. Multiple studies have shown that five days are an adequate time frame to capture daily leadership behavior and related outcomes (e.g., Diebig, Bormann, \& Rowold, 2017; Hetland et al., 2015). We invited teams from different organizations in Germany to our survey. Research assistants supported the data collection, for example by contacting team leaders or HR departments. The recruitment strategy was aimed to invite complete teams. All participating team members and the team leaders were informed about the study design (i.e., diary study) and the purpose of data collection. As a necessary condition for participation, team members had to have daily interactions with their team.

We invited team members to our survey via e-mail and sent individualized links to an online survey. At first, participants had to answer a general survey with questions regarding demographic data and trait measures of all study variables. Furthermore, they had to provide their daily end-of-work time for each day in the following week. Based on this information, daily questionnaires were sent by e-mail two hours before the daily end-of-work in the subsequent week. In addition, a second e-mail reminded participants who had not completed the daily questionnaire within 90 minutes. Access to the daily survey became invalid on the next day. All members of the same team had to participate in the same week. To ensure the anonymity of data, 
the survey-tool provided an internal code for all participants that allows matching the daily surveys and the general survey. Team affiliation was coded likewise.

In total, 198 team members from 54 teams signed up to the general survey. One team decided to withdraw their participation after completing the general survey and was excluded from the data analysis. The mean team size was $3.74(S D=1.33$, range $=3$ to 8 team members). From the initial sample, 187 team members (response rate $=94 \%$ ) from 53 teams completed the general survey and were invited to the daily survey in the subsequent week. On average, participants completed 4.33 daily questionnaires (126 completed all five daily surveys). To prevent non-response bias, we excluded 51 cases (i.e., team-days) for which only two or less team members responded per day resulting in a final sample of 725 person-days and 207 teamdays (on average 3.50 ratings per team-day and an average daily response rate of $94 \%$ for the those teams).

Participating team members were on average 36.89 years old $(S D=11.69$ years $)$ and $57 \%$ were female. More than half of the team members hold a university degree (58\%). They worked about 3.85 years with their current team $(S D=4.19$ years) and were about 8.40 years part of their organization $(S D=9.27$ years). About $61 \%$ of the team members worked in organizations with 1,000 or less employees, whereas $29 \%$ worked in organizations with 1,000 to 10,000 employees, and $10 \%$ reported to work in organizations with more than 10,000 employees. Nearly all teams were collocated (88\%) and type of communication was more direct (e.g., in meetings or face-toface talks, 91\%) than indirect (e.g., via e-mail or phone, 9\%). Participants spent about 13.33 hours per week in direct contact with their team colleagues $(S D=12.51$ hours $)$. About 20\% worked at the trading sector, followed by public administration (13\%), finance sector ( $8 \%)$ and IT sector (8\%). The team leaders were mostly male (67\%) and communicated more directly (e.g., 
in meetings or face-to-face talks, $83 \%$ ) than indirectly (e.g., via e-mail or phone, $17 \%$ ) with the team. The team members reported on average 7.43 hours per week of contact time with their team leader $(S D=9.38$ hours $)$.

\section{Measures}

The daily measures were adapted and shortened versions of validated questionnaires. We selected items based on content-related arguments and included those items, which were central for content validity and reflected behaviors that could be shown on a daily basis (Ohly et al., 2010). Due to the German-speaking sample, the questionnaires have been translated into German by the first author. The translation aimed to retain the content and meaning of the original items instead of identical wording (see Lehmann-Willenbrock \& Kauffeld, 2010) and has been checked by a bilingual speaker.

Daily shared leadership. Shared leadership was assessed following the procedure described by Carson et al. (2007). Team members mutually rated their peers (i.e., on the same hierarchical level and not the formal team leader) on the item: "To what degree did your team rely on this individual for leadership today?" on a 5-point Likert scale ranging from 1 (not at all) to 5 (to a very great extent). The sum of all ratings was divided by the number of ratings. In prior studies, this procedure proved an adequate and valid measurement of shared leadership (e.g., D'Innocenzo et al., 2016; Mathieu et al., 2015). To estimate the degree of agreement of the team member ratings, we calculated intraclass correlation (ICC1, Hox, 2010). For the daily team-level, the ICC1 refers to the ratio of day-specific shared variance between the members of a team compared to the total variance across all days (i.e., is there systematic variance in the team member ratings that can be attributed to their experience within their team on a specific day?). For the team-level, the ICC1 refers to the ratio of shared variance between the members of a 
team across all days compared to the total variance (i.e., is there systematic variance in the team member ratings that can be attributed to their team membership?). ICC1 was .16 for daily teamlevel and .25 for team-level shared leadership.

Daily cohesion. We used an adapted measurement of task cohesion (three items based on Carron, Widmeyer, \& Brawley, 1985) as used in Tekleab et al. (2009). The items were measured on a 7-point Likert scale ranging from 1 (strongly disagree) to 7 (strongly agree). A sample item was “Today, our team was united in trying to reach its goals for performance”. Cronbach's alpha based on the daily individual ratings ranged from .75 to .89 over the five working days. ICC1 was .27 for daily team-level and .24 for team-level. To additionally estimate the degree of within-group agreement, we calculated mean $r_{w g(j)}($ James, Demaree, \& Wolf, 1993) for each day. Mean $r_{w g(j)}$ was between .66 and .76.

Daily team work engagement. The questionnaire for day-level team work engagement contained an adapted and shortened version of the Team Work Engagement Scale (Costa et al., 2014a). We selected the four items that were prior used in the study of Mäkikangas, Aunola, Seppälä, and Hakanen (2016). Items were rated on a 7-point Likert scale ranging from 1 (never) to 7 (always). A sample item was “Today at work, we felt bursting with energy”. Cronbach’s alpha based on the daily individual ratings ranged from .91 to .94 over the five working days. ICC1 was .25 for daily team-level and .26 for team-level. Mean $r_{w g(j)}$ was between .72 and .83 .

Daily goal attainment. For goal attainment, participants were asked in the general survey to list - in consultation with the team - three team goals, they were currently involved in. At the daily survey, participants rated the degree of team's goal attainment with two items ("Today at work, we have made considerable progress toward attaining our goals", "Today at work, we accomplished what we set out to do with our goals") on a 6-point Likert scale from 1 
(not at all) to 6 (totally). This procedure served as a valid measurement of daily goal attainment in prior diary studies (e.g., Rodríguez-Carvajal, Herrero, van Dierendonck, Rivas, \& MorenoJiménez, 2019). Cronbach's alpha based on the daily individual ratings ranged from .80 to .92 over the five working days. ICC1 was .21 for daily team-level and .16 for team-level. Mean $r_{w g(j)}$ was between .65 and .72 .

Factorial validity. We used confirmatory factor analyses (CFA) to test factorial validity of our day-level multi-item measures (i.e., task cohesion, team work engagement, and goal attainment). Due to non-normal distributed data, we applied a robust maximum likelihood estimator (MLR) using the lavaan package (Rosseel, 2012) in R (version 4.0.3; R Core Team, 2020). The model fit of our three factor model was satisfying $\left(\chi^{2}=50.81, d f=24, p<.00\right.$, CFI $=.99, \mathrm{RMSEA}=.04, \mathrm{SRMR}=.02)$. This model obtained a better fit than multiple alternative models in which team work engagement and goal attainment $\left(\chi^{2}=367.13, d f=26, \mathrm{CFI}=.86\right.$, $\mathrm{RMSEA}=.14, \mathrm{SRMR}=.08)$, task cohesion and goal attainment $\left(\chi^{2}=336.68, d f=26, \mathrm{CFI}=.87\right.$, $\operatorname{RMSEA}=.13, \mathrm{SRMR}=.06)$, as well as task cohesion and team work engagement $\left(\chi^{2}=382.35\right.$, $d f=26, \mathrm{CFI}=.85, \mathrm{RMSEA}=.14, \mathrm{SRMR}=.09)$ respectively loaded together on one factor. Additionally, significant $\chi^{2}$-difference tests also underlined that the alternative models had a worse fit than our proposed model.

\section{Statistical analysis strategy}

To recognize the hierarchical data structure, we analyzed our data using multilevel modeling with Mplus 8.5 (L. K. Muthén \& Muthén, 1998-2017). More precisely, a three-level model was examined: The lowest level represented daily measures of individuals (Level 1 daily individual level). Those measures were nested within daily measures on team-level, representing the measure of one team at one day (Level 2 - within-team level). Those daily 
measures on team-level were nested within teams (Level 3 - between-team level). To receive unconflated estimates, we followed the centering recommendations for three-level models (Brincks et al., 2017): On Level 1, we centered predictor variables on the group mean (i.e. dayspecific mean of a team; $X_{i j k}-\bar{X}_{. j k}$ ). On Level 2, we centered the respective day-specific team mean on team-level mean $\left(\bar{X}_{. j k}-\bar{X}_{. . k}\right)$. On Level 3, we centered the team-specific mean on the grand mean $\left(\bar{X}_{. . k}-\bar{X}_{. . .}\right)$. For hypotheses testing, Level 2 is of primary interest, as this level represents the teams' day-specific relationships (i.e., within-team level). Thus, centering on the team-level mean is necessary to disaggregate the within-team relationships (i.e., on the daily team-level) from the between-team relationships (for discussion of centering decisions for longitudinal data see L. P. Wang \& Maxwell, 2015).

For model estimation, we applied a Bayesian estimator (B. O. Muthén \& Asparouhov, 2012). As recommended, we evaluated Bayesian model fit and Markov Chain Monte Carlo (MCMC) convergence by taking posterior predictive $p$-value (PPP), posterior predictive checking (PPC), potential scale reduction (PSR), trace plots and degree of autocorrelation for every estimated parameter (e.g., slopes, intercepts, residual variances) into account (Depaoli \& van de Schoot, 2017; Kaplan \& Depaoli, 2012). In total, 500,000 MCMC iterations were run with a burn-in phase of 250,000 iterations. All effects were modeled as fixed effects.

\section{Results}

The means, standard deviations, and intercorrelations are presented in Table 1. We calculated the correlations for daily individual-level, daily team-level, and team-level, respectively.

Insert Table 1 about here 
In order to obtain a more detailed view on short-term dynamics, we present some descriptive analyses before the hypotheses tests are shown. All constructs exhibited a notable amount of team-level variance that can be attributed to day-level changes on the team level (i.e., within-team variation in relation to between-team variation after aggregating the daily individual-level ratings to the daily team-level $)^{2}$. In total, results indicated $34 \%$ within-team variation for shared leadership, $50 \%$ for cohesion, $46 \%$ for team work engagement, and $65 \%$ for goal attainment. In Figure 1, the average day-specific values across all teams are presented. Accordingly, the average magnitude of team behaviors and team states slightly changed from day to day. Moreover, different patterns of short-term changes in shared leadership for five exemplary teams are presented in Figure 2. The selected teams exhibited a notable amount of fluctuations in shared leadership across the week and also showed quite different change patterns. For example, the first team had nearly a linear trend (i.e., linear increase from Monday to Friday) over the course of the week, whereas the second team showed an increase in shared leadership until the middle of the week and then stagnated until the end of the week. The third team displayed an inverted $u$-shaped change pattern with the highest level of shared leadership on Wednesday and less shared leadership at the beginning and end of the week. In contrast, the fourth and fifth team exhibited no linear or quadratic (e.g., inverted u-shaped) trend, but indicated a 'zig-zag' pattern of fluctuations across the week. Summarized, even though the average change from day-to-day across all teams was small, the descriptive results for these selected teams indicated quite diverse change patterns which may lead to the conclusion that

${ }^{2}$ It should be noted that these estimates have been calculated after aggregating the individuallevel data. Thus, the individual-level variance has been removed and these estimates refer only to the team-level variance. Nevertheless, the ratio of daily team-level variance compared to the total variance is presented in the 'Measures' section. 
short-term changes in shared leadership depend on the specific team. In the following, we describe the results for our hypotheses tests.

Insert Figure 1 about here

Insert Figure 2 about here

We tested our hypotheses within one statistical model. The model showed a good fit: The posterior-predictive $p$-value was larger than the supposed cut-off of .05 and the confidence interval for the posterior predictive checking included zero $(\mathrm{PPP}=.61 ; \mathrm{PPC}=[-28.78 ; 20.94])$. The ratio of within and between scale variation (potential scale reduction) decreased swiftly over the iterations, and remained under 1.01 after approximately 48.000 iterations. Furthermore, trace plots showed a typical pattern of MCMC convergence for all parameters. The autocorrelation plots indicated a moderate degree of autocorrelation for some estimates and, thus, we used only every $10^{\text {th }}$ iteration to reduce the degree of autocorrelation (see Depaoli \& van de Schoot, 2017).

The results of our Bayesian multilevel model are shown in Figure 3. In support for Hypothesis 1 , daily shared leadership was positively associated with daily cohesion, as the posterior distribution excluded zero as plausible value $(\beta=.43,95 \%-\mathrm{CI}=[.31 ; .53])$. Regarding Hypothesis 2 , day-level shared leadership was related to team work engagement $(\beta=.37,95 \%$ $\mathrm{CI}=[.15 ; .57])$ over and above the influence of day-level cohesion $(\beta=.71,95 \%-\mathrm{CI}=$ $[.52 ; .87])$. Thus, Hypothesis 2 received support. In line with Hypothesis 3, daily shared leadership was positively linked to daily goal attainment $(\beta=.33,95 \%-\mathrm{CI}=[.12 ; .53])$, over and above the impact of day-level cohesion $(\beta=.66,95 \%-\mathrm{CI}=[.45 ; .85])$. 
As our multilevel model also included the between-team results, we present them hereafter. The pattern of results on the between-team level differed from the within-team findings. Shared leadership was not related to cohesion, team work engagement, nor goal attainment, as the posterior distributions included zero as plausible value for these relationships. In contrast, cohesion was linked to team work engagement $(\beta=.75,95 \%-C I=[.55 ; .87])$ and goal attainment respectively $(\beta=.67,95 \%-\mathrm{CI}=[.41 ; .84])$.

Insert Figure 3 about here

\section{Supplementary analysis}

In order to review our results from Bayesian model estimation, we supplemented our analysis with maximum likelihood estimation. The fit of the tested model was good $\left(\chi^{2}=0.08, d f\right.$ $=5, p=.99, \mathrm{CFI}=1.00, \mathrm{RMSEA}=.00, \mathrm{SRMR}_{\text {daily-person }}=.00, \mathrm{SRMR}_{\text {daily-team }}=.00, \mathrm{SRMR}_{\text {team }}$ $=.00)$. The pattern of results was highly comparable with the Bayesian estimation and revealed the same conclusions regarding the hypotheses.

To take a detailed view on day-level shared leadership, several supplementary analyses have been conducted. At first, most team members participated on all of the five days. However, day-level shared leadership may also fluctuate due to non-response of the team members. To rule out this possibility, we reanalyzed our model with a subsample that only contains those teams for which all team members respond on all days. The resulting sample sizes were 395 person-days, 125 team-days, and 25 teams. The model fit was good $(\mathrm{PPP}=.57 ; \mathrm{PPC}=[-28.76 ; 24.75])$. The results were similar to the full-sample model, as shared leadership was related to cohesion ( $\beta$ $=.49,95 \%-\mathrm{CI}=[.34 ; .61])$, team work engagement $(\beta=.34,95 \%-\mathrm{CI}=[.10 ; .58])$, and goal 
attainment $(\beta=.43,95 \%-\mathrm{CI}=[.21 ; .63])$ on the day-level (the complete results are presented as an online supplement in Figure S1).

Next, we have examined lagged effects on next-day team work engagement and goal attainment (the complete results are presented as an online supplement in Figure S2). The results of this supplementary analysis revealed that shared leadership and cohesion were both not related to next-day team work engagement and goal attainment, as the posterior distributions for these relationships included zero.

\section{Discussion}

The overall aim of this study was to extend the nomological network of shared leadership for a within-team perspective with a focus on daily changes. For that purpose, we have tested the links of shared leadership with cohesion, team engagement, and goal attainment on the day-level. In general, the results supported our hypotheses: Higher day-level shared leadership was positively related to team cohesion, team work engagement, and goal attainment. Accordingly, on days with above-average shared leadership behaviors (i.e., structuring tasks, providing feedback, solving problems, or managing the social climate; Morgeson et al., 2010), team members will more likely facilitate their collaboration within the team, collectively experience higher engagement, and show a greater progress in attaining common goals. Apart from these findings, we provided a descriptive analysis of shared leadership fluctuations which reflects the dynamic nature of this team state.

\section{Theoretical contributions}

The results of this study can expand the current knowledge about shared leadership by providing the following contributions to the literature. However, due to the correlational nature of our study, we have to point out that our conclusions regarding the theoretical contributions 
have to be interpreted with caution (e.g., with respect to reverse causality). First, the results of the daily diary study point to within-team changes in shared leadership, cohesion, and related outcomes. Our descriptive analyses showed that about $34 \%$ to $65 \%$ of the team-level variance could be due to day-level changes. Accordingly, variations in our focal team constructs could be separated in within (i.e., variation in one team over time) and between (i.e., variation between different teams) parts, which further underlines the need to capture temporal dynamics of team phenomena. With regard to shared leadership, its day-level magnitude varied across the week and the pattern of change differed between teams. This result supports the theoretical assumptions about the dynamic nature of shared leadership (D'Innocenzo et al., 2016; Kozlowski et al., 2016; Pearce \& Conger, 2003). In addition, this finding may reveal some similarities to current findings about short-term changes in formal leadership and related day-level outcomes (see Kelemen et al., 2020; McClean et al., 2019). Furthermore, our results extend prior empirical work about long-term changes in shared leadership (Drescher et al., 2014) by showing that this team state varies not only in the long run, but is actually subject to short-term changes on a daily basis. This is an important finding which underlines that team leadership and more generally team phenomena need to be studied from a within-team perspective (cf. Kozlowski, 2015).

Second, our results could show that day-level shared leadership is likely related to daylevel cohesion, team work engagement, and goal attainment. This adds a within-team perspective to the nomological network of leadership. Accordingly, teams, which show more day-specific leading-following interactions relative to their average level of shared leadership, tend to be more cohesive, develop a greater collective engagement, and show a greater progress in attaining team goals on these days. Hence, teams with a generally low level of shared leadership can also benefit from this form of team leadership, as they may adapt their day-level shared leadership 
behavior to fulfill their daily needs. Furthermore, this finding also adds to the literature of team work engagement by linking it with day-level shared leadership. Research about antecedents of team work engagement is scarce (Costa et al., 2014a) and team leadership has not yet been examined as a possible promotor of team work engagement. Likewise, the day-level findings speak to the dynamic nature of this emergent team state, as its individual-level counterpart (i.e., individual work engagement) has already been proven to be sensitive to changes on a daily level (see Bakker, 2014).

Third, we examined how shared leadership is related to outcomes across multiple levels of analysis (cf. Gabriel et al., 2018; Kelemen et al., 2020). From this multilevel perspective, the within- and the between-team level findings actually differed, which is in line with differences in prior within-person research about formal leadership (see McCormick, Reeves, Downes, Li, \& Ilies, 2020). In our study, we did not find evidence that shared leadership is related to collective engagement and goal attainment on the between-team level. Teams, which have generally high levels of shared leadership, do not necessarily develop greater team work engagement or work more effectively. Yet, the within-team changes seem to account for the engaging and performance-enhancing potential of shared leadership in this study. Hence, this diary study can give a nuanced view on the outcomes of shared leadership and could reveal differences between levels. However, it was still surprising that shared leadership was unrelated to our outcomes at the between-team level relative to the performance-enhancing findings for general levels of shared leadership in past studies and meta-analyses (e.g., D’Innocenzo et al., 2016; Zhu et al., 2018). A possible explanation might be that we measured shared leadership only for five days with a day-specific measure. This period of time could be too short to capture the 'true' between- 
team level amount of shared leadership. With regard to this, the between-team findings have to be interpreted with caution.

Moreover, it may be important to consider the timeframe in which shared leadership is related to outcomes. Following the suggestion of an anonymous reviewer, we tested for timelagged relationships. The results of this supplementary analysis showed that day-level shared leadership was not related to next-day team work engagement or goal attainment. While lagged effects are less affected by common method variance (cf. Podsakoff, MacKenzie, Lee, \& Podsakoff, 2003), this missing lagged relationship may also be explained by the timing of our measures. We measured our focal constructs at the end of the working day. Nevertheless, it may be possible that previous-day shared leadership can only influence teamwork at the beginning of the next day without a persistent influence on the whole day. Beyond the scope of our study, this result is also interesting in the light of recent findings about day-level formal or hierarchical leadership. Some studies have shown that formal leadership may affect outcomes across days (Kuonath et al., 2017) or weeks (Breevaart \& Zacher, 2019), and thus may have longer persistent relationships with outcomes. A possible explanation might be that team members have more contact with their peers and informal leadership (i.e., shared leadership) could be both a lowthreshold and a more immediate source of team leadership compared to formal leadership. Thus, day-level shared leadership might operate more proximally and may only be relevant on the same day. More research is needed to examine the time-lagged consequences of different forms of day-level leadership (see also Kelemen et al., 2020).

\section{Practical implications}

Based on the results of this study, there are possible implications for team leaders, managers, and HR practitioners. Our findings underline that shared leadership may be important 
for daily teamwork. When teams practice shared leadership, they may experience more team work engagement and show greater progress in attaining team goals. As shared leadership can vary from day-to-day, teams may use this informal source of team leadership especially in critical project stages or challenging situations to promote goal attainment (i.e., team effectiveness). Relatedly, sharing leadership functions in the team can help to keep the team cohesive and focused on a shared purpose.

In general, organizations should consider the concept of shared leadership and facilitate the emergence of this phenomenon. Team development and training programs can help teams to utilize shared leadership for their team and task work. For example, Drescher and colleagues (2014) suggested that training on mental models can support teams to establish shared leadership. Organizations should also make team leaders aware of the beneficial consequences of shared leadership. If team leaders understand and accept informal leadership influence from their teams, this may improve team effectiveness. For example, team leaders' transformational and empowering leadership behavior can foster shared leadership by focusing on collective goals and empowerment of their teams (Grille, Schulte, \& Kauffeld, 2015; Hoch, 2013; Klasmeier \& Rowold, 2020). Sharing power and providing autonomy can encourage teams to take the lead. Furthermore, team leaders should behave consistently towards all team members, as a differentiation in the leader-follower relationships throughout the team can diminish shared leadership (L. Wang, Jiang, Liu, \& Ma, 2017).

\section{Limitations and future directions}

In the following, we discuss several methodological and theoretical shortcomings of this study. Our results are based on a correlational design and which does not allow for a causal interpretation. This limitation is further emphasized by the absence of lagged effects. Thus, the 
findings cannot be interpreted in a temporal direction and reverse causality may be an option. Hence, within-team changes in shared leadership might also be triggered by changes in cohesion, team work engagement, or goal attainment. Moreover, omitted variables may raise concerns about endogeneity (Antonakis, Bendahan, Jacquart, \& Lalive, 2010). In order to remove between-team differences that may influence the results, we centered our data on the respective team mean and added the team mean on Level 3. This procedure allows to estimate the withinteam relationships without confounding effects of between-team differences (see Antonakis et al., 2019). Nevertheless, day-level formal leadership may be a plausible alternative to explain our pattern of results, although recent meta-analyses suggested that shared leadership may be important for team effectiveness beyond the influence of formal leadership (Nicolaides et al., 2014; D. Wang et al., 2014). Thus, we urge future research to include different sources of team leadership (e.g., formal and shared leadership) and compare their influence on day-specific team engagement and goal attainment. Besides formal leadership, other omitted variables and daylevel confounds may influence the relation between shared leadership and the considered outcomes. To at least partially account for possible day-level confounds, we controlled for cohesion, as day-level changes in cohesion may for example reflect social exchange processes or conflicts within the team to a certain degree (Kozlowski \& Chao, 2012). Further studies may consider additional day-level third variables like changes in the team task or workload for a more robust examination of the relation between shared leadership and its day-level outcomes.

The self-reported data may raise the concern about common method bias (Podsakoff et al., 2003). Especially for goal attainment, the self-serving bias may influence the rating. However, as we focus on the (daily) team-level, the rating of the constructs does not rely on a single individual, but on the consensus of all team members on a given day. Furthermore, for a 
daily-diary design, the inclusion of other-source ratings (i.e., team leader) may lead to problems concerning the accuracy of these ratings. As recently suggested by Gabriel et al. (2018), emotional states, thoughts, perceptions, and behaviors are often captured most accurately by the individuals experiencing them. Likewise, the accurate rating of visible behavior (i.e., goal attainment) depends on the frequency of interactions (Gabriel et al., 2018). In this sample, 70\% of the participants reported an average contact time (direct and indirect contact) with their team leader of only five or less hours per week $(M=7.43$ hours, median $=3.00$ hours, $S D=9.38$ hours), so the team leaders may not always be aware of the team's daily progress in goal attainment. We suggest that further research can address this issue by using a longer time interval. For example, Breevaart, Bakker, Demerouti, and Derks (2016) used a weekly-diary design to investigate the influence of vertical leadership on work engagement and individual job performance.

Another limitation relates to the measurement of shared leadership. We concentrated on the overall amount of day-level shared leadership, which is suitable to capture within-team changes (due to group-mean centering) and which is also a typical approach for diary studies about leadership behavior in general (Kelemen et al., 2020). However, as suggested by an anonymous reviewer, shifts in the leadership roles of the different team members (i.e., who displays leading or following behaviors and when are these behaviors shown) across the days are a reasonable alternative to study shared leadership dynamics besides our perspective on withinteam changes relative to between-team differences (see also L. Wang, Han, Fisher, \& Pan, 2017). Accordingly, further studies may consider which aspects might predict day-specific shifts in leadership roles and whether these shifts are related to team outcomes. Moreover, besides the rather broad measure of shared leadership in terms of the amount of leadership influence in the 
team, it may also be possible to assess the degree to which the team fulfills different leadership functions on a given day (Morgeson et al., 2010; for a recent discussion of measurement decisions about shared leadership see Zhu et al., 2018). For example, He et al. (2020) as well as Hiller, Day, and Vance (2006) used this approach to measure shared leadership in between-team settings. Future studies may use and compare different measures to get a more nuanced view of within-team changes in shared leadership.

This study deals with the outcomes of within-team changes in shared leadership, but does not include antecedents of these changes. As stated earlier, day-level shared leadership may depend on the team environment, interactions, and current tasks (DeRue \& Ashford, 2010; Kozlowski et al., 2016; Marks et al., 2001). In line with a recent call for further research addressing the dynamics and antecedents of shared leadership (Kozlowski et al., 2016), additional diary studies can examine which factors may influence day-level shared leadership.

At last, this is one of the first diary studies with teams and, thus, our results have to be interpreted with caution in terms of statistical power and required sample sizes. In total, we had a sample of 53 teams and 207 team-days for Level 3 and Level 2. However, these sample sizes may be difficult to compare with recent benchmarks for diary studies (see Gabriel et al., 2018), as these benchmarks refer to diary studies with individuals and not teams. In addition, we only studied shared leadership over five working days. Although this is a typical timeframe for diary studies about leadership (see Kelemen et al., 2020), a longer period of time (e.g., ten days) would have increased the Level 2 sample size. Accordingly, simulation studies are needed to provide guidelines and recommendations about sufficient statistical power and required sample sizes in three-level models for diary studies with teams. 


\section{Conclusion}

This study provides new insights about the within-team relationships of shared leadership with cohesion, team work engagement, and goal attainment. Day-level shared leadership can facilitate the experience of being cohesive as a team. Additionally, above-average leadingfollowing interactions between the members of a team are associated with higher day-level team vigor, dedication, and absorption as well as greater progress in attaining collective goals. As the research on day-level dynamics of team processes and emergent states is still in its infancy, this investigation provides several directions for further studies. 


\section{References}

Antonakis, J., Bastardoz, N., \& Rönkkö, M. (2019). On Ignoring the Random Effects Assumption in Multilevel Models: Review, Critique, and Recommendations. Organizational Research Methods, 109442811987745. https://doi.org/10.1177/1094428119877457

Antonakis, J., Bendahan, S., Jacquart, P., \& Lalive, R. (2010). On making causal claims: A review and recommendations. The Leadership Quarterly, 21(6), 1086-1120. https://doi.org/10.1016/j.leaqua.2010.10.010

Aubé, C., Rousseau, V., \& Brunelle, E. (2018). Flow experience in teams: The role of shared leadership. Journal of Occupational Health Psychology, 23(2), 198-206. https://doi.org/10.1037/ocp0000071

Bakker, A. B. (2014). Daily fluctuations in work engagement: An overview and current directions. European Psychologist, 19(4), 227-236. https://doi.org/10.1027/1016$9040 / \mathrm{a} 000160$

Bergman, J. Z., Rentsch, J. R., Small, E. E., Davenport, S. W., \& Bergman, S. M. (2012). The shared leadership process in decision-making teams. The Journal of Social Psychology, 152(1), 17-42. https://doi.org/10.1080/00224545.2010.538763

Bormann, K. C. (2017). Linking daily ethical leadership to followers' daily behaviour: The roles of daily work engagement and previous abusive supervision. European Journal of Work and Organizational Psychology, 26(4), 590-600. https://doi.org/10.1080/1359432X.2017.1331217

Breevaart, K., Bakker, A. B., Demerouti, E., \& Derks, D. (2016). Who takes the lead? A multisource diary study on leadership, work engagement, and job performance. Journal of Organizational Behavior, 37(3), 309-325. https://doi.org/10.1002/job.2041 
Breevaart, K., \& Zacher, H. (2019). Main and interactive effects of weekly transformational and laissez - faire leadership on followers' trust in the leader and leader effectiveness. Journal of Occupational and Organizational Psychology, 92(2), 384-409. https://doi.org/10.1111/joop.12253

Brincks, A. M., Enders, C. K., Llabre, M. M., Bulotsky-Shearer, R. J., Prado, G., \& Feaster, D. J. (2017). Centering predictor variables in three-level contextual models. Multivariate Behavioral Research, 52(2), 149-163. https://doi.org/10.1080/00273171.2016.1256753

Carron, A. V., Widmeyer, W. N., \& Brawley, L. R. (1985). The development of an instrument to assess cohesion in sport teams: The group environment questionnaire. Journal of Sport Psychology, 7(3), 244-266. https://doi.org/10.1123/jsp.7.3.244

Carson, J. B., Tesluk, P. E., \& Marrone, J. A. (2007). Shared leadership in teams: An investigation of antecedent conditions and performance. Academy of Management Journal, 50(5), 1217-1234. https://doi.org/10.5465/amj.2007.20159921

Castaño, N., Watts, T., \& Tekleab, A. G. (2013). A reexamination of the cohesion-performance relationship meta-analyses: A comprehensive approach. Group Dynamics: Theory, Research, and Practice, 17(4), 207-231. https://doi.org/10.1037/a0034142

Chan, D. (1998). Functional relations among constructs in the same content domain at different levels of analysis: A typology of composition models. Journal of Applied Psychology, 83(2), 234-246. https://doi.org/10.1037/0021-9010.83.2.234

Chiu, C.-Y. C., Owens, B. P., \& Tesluk, P. E. (2016). Initiating and utilizing shared leadership in teams: The role of leader humility, team proactive personality, and team performance capability. Journal of Applied Psychology, 101(12), 1705-1720.

https://doi.org/10.1037/ap10000159 
Contractor, N. S., DeChurch, L. A., Carson, J. B., Carter, D. R., \& Keegan, B. (2012). The topology of collective leadership. The Leadership Quarterly, 23(6), 994-1011. https://doi.org/10.1016/j.leaqua.2012.10.010

Costa, P. L., Passos, A. M., \& Bakker, A. B. (2014a). Empirical validation of the team work engagement construct. Journal of Personnel Psychology, 13(1), 34-45. https://doi.org/10.1027/1866-5888/a000102

Costa, P. L., Passos, A. M., \& Bakker, A. B. (2014b). Team work engagement: A model of emergence. Journal of Occupational and Organizational Psychology, 87(2), 414-436. https://doi.org/10.1111/joop.12057

D’Innocenzo, L., Mathieu, J. E., \& Kukenberger, M. R. (2016). A meta-analysis of different forms of shared leadership-team performance relations. Journal of Management, 42(7), 1964-1991. https://doi.org/10.1177/0149206314525205

Day, D. V., Gronn, P., \& Salas, E. (2004). Leadership capacity in teams. The Leadership Quarterly, 15(6), 857-880. https://doi.org/10.1016/j.leaqua.2004.09.001

Deci, E. L., Olafsen, A. H., \& Ryan, R. M. (2017). Self-determination theory in work organizations: The state of a science. Annual Review of Organizational Psychology and Organizational Behavior, 4(1), 19-43. https://doi.org/10.1146/annurev-orgpsych-032516113108

Depaoli, S., \& van de Schoot, R. (2017). Improving transparency and replication in Bayesian statistics: The WAMBS-Checklist. Psychological Methods, 22(2), 240-261. https://doi.org/10.1037/met0000065 
DeRue, D. S. (2011). Adaptive leadership theory: Leading and following as a complex adaptive process. Research in Organizational Behavior, 31, 125-150. https://doi.org/10.1016/j.riob.2011.09.007

DeRue, D. S., \& Ashford, S. J. (2010). Who will lead and who will follow? A social process of leadership identity construction in organizations. Academy of Management Review, 35(4), 627-647. https://doi.org/10.5465/amr.35.4.zok627

Diebig, M., Bormann, K. C., \& Rowold, J. (2017). Day-level transformational leadership and followers' daily level of stress: A moderated mediation model of team cooperation, role conflict, and type of communication. European Journal of Work and Organizational Psychology, 26(2), 234-249. https://doi.org/10.1080/1359432X.2016.1250741

Drescher, M. A., Korsgaard, M. A., Welpe, I. M., Picot, A., \& Wigand, R. T. (2014). The dynamics of shared leadership: Building trust and enhancing performance. Journal of Applied Psychology, 99(5), 771-783. https://doi.org/10.1037/a0036474

Gabriel, A. S., Podsakoff, N. P., Beal, D. J., Scott, B. A., Sonnentag, S., Trougakos, J. P., \& Butts, M. M. (2018). Experience sampling methods: A discussion of critical trends and considerations for scholarly advancement. Organizational Research Methods, 63(3). https://doi.org/10.1177/1094428118802626

Grille, A., Schulte, E.-M ., \& Kauffeld, S. (2015). Promoting shared leadership: A multilevel analysis investigating the role of prototypical team leader behavior, psychological empowerment, and fair rewards. Journal of Leadership \& Organizational Studies, 22(3), 324339. https://doi.org/10.1177/1548051815570039

He, W., Hao, P., Huang, X., Long, L.-R., Hiller, N. J., \& Li, S.-L. (2020). Different roles of shared and vertical leadership in promoting team creativity: Cultivating and synthesizing team 
members' individual creativity. Personnel Psychology, 73(1), 199-225.

https://doi.org/10.1111/peps. 12321

Hetland, J., Hetland, H., Bakker, A. B., Demerouti, E., Andreassen, C. S., \& Pallesen, S. (2015).

Psychological need fulfillment as a mediator of the relationship between transformational leadership and positive job attitudes. Career Development International, 20(5), 464-481. https://doi.org/10.1108/CDI-10-2014-0136

Hiller, N. J., Day, D. V., \& Vance, R. J. (2006). Collective enactment of leadership roles and team effectiveness: A field study. The Leadership Quarterly, 17(4), 387-397.

https://doi.org/10.1016/j.leaqua.2006.04.004

Hoch, J. E. (2013). Shared leadership and innovation: The role of vertical leadership and employee integrity. Journal of Business and Psychology, 28(2), 159-174.

https://doi.org/10.1007/s10869-012-9273-6

Hox, J. J. (2010). Multilevel analysis: Techniques and applications (2. ed.). Quantitative methodology series. New York, NY: Routledge.

Humphrey, S. E., \& Aime, F. (2014). Team microdynamics: Toward an organizing approach to teamwork. Academy of Management Annals, 8(1), 443-503.

https://doi.org/10.1080/19416520.2014.904140

James, L. R., Demaree, R. G., \& Wolf, G. (1993). rwg: An assessment of within-group interrater agreement. Journal of Applied Psychology, 78(2), 306-309. https://doi.org/10.1037/00219010.78 .2 .306

Kaplan, D., \& Depaoli, S. (2012). Bayesian structural equation modeling. In R. H. Hoyle (Ed.), Handbook of structural equation modeling (pp. 650-673). New York, NY: Guilford Press. 
Kelemen, T. K., Matthews, S. H., \& Breevaart, K. (2020). Leading day-to-day: A review of the daily causes and consequences of leadership behaviors. The Leadership Quarterly, 31(1), 101344. https://doi.org/10.1016/j.leaqua.2019.101344

Klasmeier, K. N., \& Rowold, J. (2020). A multilevel investigation of predictors and outcomes of shared leadership. Journal of Organizational Behavior, 41(9), 915-930. https://doi.org/10.1002/job.2477

Kozlowski, S. W. J. (2015). Advancing research on team process dynamics: Theoretical, methodological, and measurement considerations. Organizational Psychology Review, 5(4), 270-299. https://doi.org/10.1177/2041386614533586

Kozlowski, S. W. J., \& Chao, G. T. (2012). The dynamics of emergence: Cognition and cohesion in work teams. Managerial and Decision Economics, 33(5-6), 335-354. https://doi.org/10.1002/mde.2552

Kozlowski, S. W. J., \& Chao, G. T. (2018). Unpacking team process dynamics and emergent phenomena: Challenges, conceptual advances, and innovative methods. American Psychologist, 73(4), 576-592. https://doi.org/10.1037/amp0000245

Kozlowski, S. W. J., Chao, G. T., Grand, J. A., Braun, M. T., \& Kuljanin, G. (2013). Advancing multilevel research design: Capturing the dynamics of emergence. Organizational Research Methods, 16(4), 581-615. https://doi.org/10.1177/1094428113493119

Kozlowski, S. W. J., \& Ilgen, D. R. (2006). Enhancing the effectiveness of work groups and teams. Psychological Science in the Public Interest, 7(3), 77-124. https://doi.org/10.1111/j.1529-1006.2006.00030.x

Kozlowski, S. W. J., \& Klein, K. J. (2000). A multilevel approach to theory and research in organizations: Contextual, temporal, and emergent processes. In K. J. Klein \& S. W. J. 
Kozlowski (Eds.), Multilevel theory, research, and methods in organizations: Foundations, extensions, and new directions (pp. 3-90). San Francisco: Jossey-Bass.

Kozlowski, S. W. J., Mak, S., \& Chao, G. T. (2016). Team-centric leadership: An integrative review. Annual Review of Organizational Psychology and Organizational Behavior, 3(1), 2154. https://doi.org/10.1146/annurev-orgpsych-041015-062429

Kukenberger, M. R., \& D'Innocenzo, L. (2020). The building blocks of shared leadership: The interactive effects of diversity types, team climate, and time. Personnel Psychology, 73(1), 125-150. https://doi.org/10.1111/peps.12318

Kuonath, A., Specht, J., Kühnel, J., Pachler, D., \& Frey, D. (2017). Keeping up day-specific effects of transformational leadership: The role of followers' emotion regulation. European Journal of Work and Organizational Psychology, 26(6), 828-843.

https://doi.org/10.1080/1359432X.2017.1379993

Lehmann-Willenbrock, N., \& Kauffeld, S. (2010). Development and construct validation of the German Workplace Trust Survey (G-WTS). European Journal of Psychological Assessment, 26(1), 3-10. https://doi.org/10.1027/1015-5759/a000002

Liang, H.-Y., Shih, H.-A., \& Chiang, Y.-H. (2015). Team diversity and team helping behavior: The mediating roles of team cooperation and team cohesion. European Management Journal, 33(1), 48-59. https://doi.org/10.1016/j.emj.2014.07.002

Lorinkova, N. M., \& Bartol, K. M. (2021). Shared leadership development and team performance: A new look at the dynamics of shared leadership. Personnel Psychology, 74(1), 77-107. https://doi.org/10.1111/peps.12409 
Mäkikangas, A., Aunola, K., Seppälä, P., \& Hakanen, J. (2016). Work engagement-team performance relationship: Shared job crafting as a moderator. Journal of Occupational and Organizational Psychology, 89(4), 772-790. https://doi.org/10.1111/joop.12154

Marks, M. A., Mathieu, J. E., \& Zaccaro, S. J. (2001). A temporally based framework and taxonomy of team processes. Academy of Management Review, 26(3), 356-376. https://doi.org/10.2307/259182

Mathieu, J. E., Hollenbeck, J. R., van Knippenberg, D., \& Ilgen, D. R. (2017). A century of work teams in the Journal of Applied Psychology. Journal of Applied Psychology, 102(3), 452-467. https://doi.org/10.1037/ap10000128

Mathieu, J. E., Kukenberger, M. R., D’Innocenzo, L., \& Reilly, G. (2015). Modeling reciprocal team cohesion-performance relationships, as impacted by shared leadership and members' competence. Journal of Applied Psychology, 100(3), 713-734.

https://doi.org/10.1037/a0038898

Mathieu, J. E., Maynard, M. T., Rapp, T., \& Gilson, L. (2008). Team effectiveness 1997-2007: A review of recent advancements and a glimpse into the future. Journal of Management, 34(3), 410-476. https://doi.org/10.1177/0149206308316061

McClean, S. T., Barnes, C. M., Courtright, S. H., \& Johnson, R. E. (2019). Resetting the clock on dynamic leader behaviors: A conceptual integration and agenda for future research. Academy of Management Annals, 13(2), 479-508. https://doi.org/10.5465/annals.2017.0081

McCormick, B. W., Reeves, C. J., Downes, P. E., Li, N., \& Ilies, R. (2020). Scientific contributions of within-person research in management: Making the juice worth the squeeze. Journal of Management, 46(2), 321-350. https://doi.org/10.1177/0149206318788435 
McGrath, J. E. (1962). Leadership behavior: Some requirements for leadership training. Washington, DC: U.S. Civil Service Commission, Office of Career Development.

Morgeson, F. P., DeRue, D. S., \& Karam, E. P. (2010). Leadership in teams: A functional approach to understanding leadership structures and processes. Journal of Management, 36(1), 5-39. https://doi.org/10.1177/0149206309347376

Mullen, B., \& Copper, C. (1994). The relation between group cohesiveness and performance: An integration. Psychological Bulletin, 115(2), 210-227. https://doi.org/10.1037/00332909.115.2.210

Muthén, B. O., \& Asparouhov, T. (2012). Bayesian structural equation modeling: A more flexible representation of substantive theory. Psychological Methods, 17(3), 313-335. https://doi.org/10.1037/a0026802

Muthén, L. K., \& Muthén, B. O. (1998-2017). Mplus User's Guide. Eighth Edition. Los Angeles, CA: Muthén \& Muthén.

Nicolaides, V. C., LaPort, K. A., Chen, T. R., Tomassetti, A. J., Weis, E. J., Zaccaro, S. J., \& Cortina, J. M. (2014). The shared leadership of teams: A meta-analysis of proximal, distal, and moderating relationships. The Leadership Quarterly, 25(5), 923-942. https://doi.org/10.1016/j.leaqua.2014.06.006

Ohly, S., Sonnentag, S., Niessen, C., \& Zapf, D. (2010). Diary studies in organizational research. Journal of Personnel Psychology, 9(2), 79-93. https://doi.org/10.1027/1866-5888/a000009

Pearce, C. L. (2004). The future of leadership: Combining vertical and shared leadership to transform knowledge work. Academy of Management Perspectives, 18(1), 47-57. https://doi.org/10.5465/ame.2004.12690298 
Pearce, C. L., \& Conger, J. A. (Eds.) (2003). Shared leadership: Reframing the hows and whys of leadership. Thousand Oaks, CA: Sage.

Podsakoff, P. M., MacKenzie, S. B., Lee, J.-Y., \& Podsakoff, N. P. (2003). Common method biases in behavioral research: A critical review of the literature and recommended remedies. Journal of Applied Psychology, 88(5), 879-903. https://doi.org/10.1037/0021-9010.88.5.879

R Core Team (2020). R: A language and environment for statistical computing. Vienna, Austria: R Foundation for Statistical Computing.

Rodríguez-Carvajal, R., Herrero, M., van Dierendonck, D., Rivas, S. de, \& Moreno-Jiménez, B. (2019). Servant leadership and goal attainment through meaningful life and vitality: A diary study. Journal of Happiness Studies, 20(2), 499-521. https://doi.org/10.1007/s10902-0179954-y

Rodríguez-Sánchez, A. M., Devloo, T., Rico, R., Salanova, M., \& Anseel, F. (2017). What makes creative teams tick? Cohesion, engagement, and performance across creativity tasks: A threewave study. Group \& Organization Management, 42(4), 521-547. https://doi.org/10.1177/1059601116636476

Rosseel, Y. (2012). lavaan: An R package for structural equation modeling. Journal of Statistical Software, 48(2). https://doi.org/10.18637/jss.v048.i02

Tekleab, A. G., Quigley, N. R., \& Tesluk, P. E. (2009). A longitudinal study of team conflict, conflict management, cohesion, and team effectiveness. Group \& Organization Management, 34(2), 170-205. https://doi.org/10.1177/1059601108331218

Tims, M., Bakker, A. B., \& Xanthopoulou, D. (2011). Do transformational leaders enhance their followers' daily work engagement? The Leadership Quarterly, 22(1), 121-131. https://doi.org/10.1016/j.leaqua.2010.12.011 
Torrente, P., Salanova, M., Llorens, S., \& Schaufeli, W. B. (2012). Teams make it work: How team work engagement mediates between social resources and performance in teams. Psicothema, 24, 106-112.

Wang, D., Waldman, D. A., \& Zhang, Z. (2014). A meta-analysis of shared leadership and team effectiveness. Journal of Applied Psychology, 99(2), 181-198. https://doi.org/10.1037/a0034531

Wang, L., Han, J., Fisher, C. M., \& Pan, Y. (2017). Learning to share: Exploring temporality in shared leadership and team learning. Small Group Research, 48(2), 165-189. https://doi.org/10.1177/1046496417690027

Wang, L., Jiang, W., Liu, Z., \& Ma, X. (2017). Shared leadership and team effectiveness: The examination of LMX differentiation and servant leadership on the emergence and consequences of shared leadership. Human Performance, 30(4), 155-168. https://doi.org/10.1080/08959285.2017.1345909

Wang, L. P., \& Maxwell, S. E. (2015). On disaggregating between-person and within-person effects with longitudinal data using multilevel models. Psychological Methods, 20(1), 63-83. https://doi.org/10.1037/met0000030

Zaccaro, S. J., Rittman, A. L., \& Marks, M. A. (2001). Team leadership. The Leadership Quarterly, 12(4), 451-483. https://doi.org/10.1016/S1048-9843(01)00093-5

Zhu, J., Liao, Z., Yam, K. C., \& Johnson, R. E. (2018). Shared leadership: A state-of-the-art review and future research agenda. Journal of Organizational Behavior, 39(7), 834-852. https://doi.org/10.1002/job.2296 
Table 1

Descriptive statistics and intercorrelations

\begin{tabular}{|c|c|c|c|c|}
\hline & 1. & 2. & 3. & 4. \\
\hline \multicolumn{5}{|c|}{ Daily Person-Level $(N=697-710)$} \\
\hline \multicolumn{5}{|l|}{ 1. Shared leadership } \\
\hline 2. Cohesion & $.30 * *$ & & & \\
\hline 3. Team work engagement & $.27 * *$ & $.44 * *$ & & \\
\hline 4. Goal attainment & $.21 * *$ & $.48 * *$ & $.56^{* *}$ & \\
\hline \multicolumn{5}{|c|}{ Daily Team-Level $(N=207)$} \\
\hline \multicolumn{5}{|l|}{ 1. Shared leadership } \\
\hline 2. Cohesion & $.43 * *$ & & & \\
\hline 3. Team work engagement & $.48 * *$ & $.60^{* *}$ & & \\
\hline 4. Goal attainment & $.43 * *$ & $.54 * *$ & $.67 * *$ & \\
\hline \multicolumn{5}{|c|}{ Team-Level $(N=47)$} \\
\hline \multicolumn{5}{|l|}{ 1. Shared leadership } \\
\hline 2. Cohesion & .11 & & & \\
\hline 3. Team work engagement & -.01 & $.71 * *$ & & \\
\hline 4. Goal attainment & .07 & $.59 * *$ & $.44 * *$ & \\
\hline$M$ & 3.64 & 5.14 & 4.88 & 4.11 \\
\hline$S D$ & 0.91 & 1.37 & 1.31 & 1.18 \\
\hline
\end{tabular}

$* p<.05$

$* * p<.01$ 


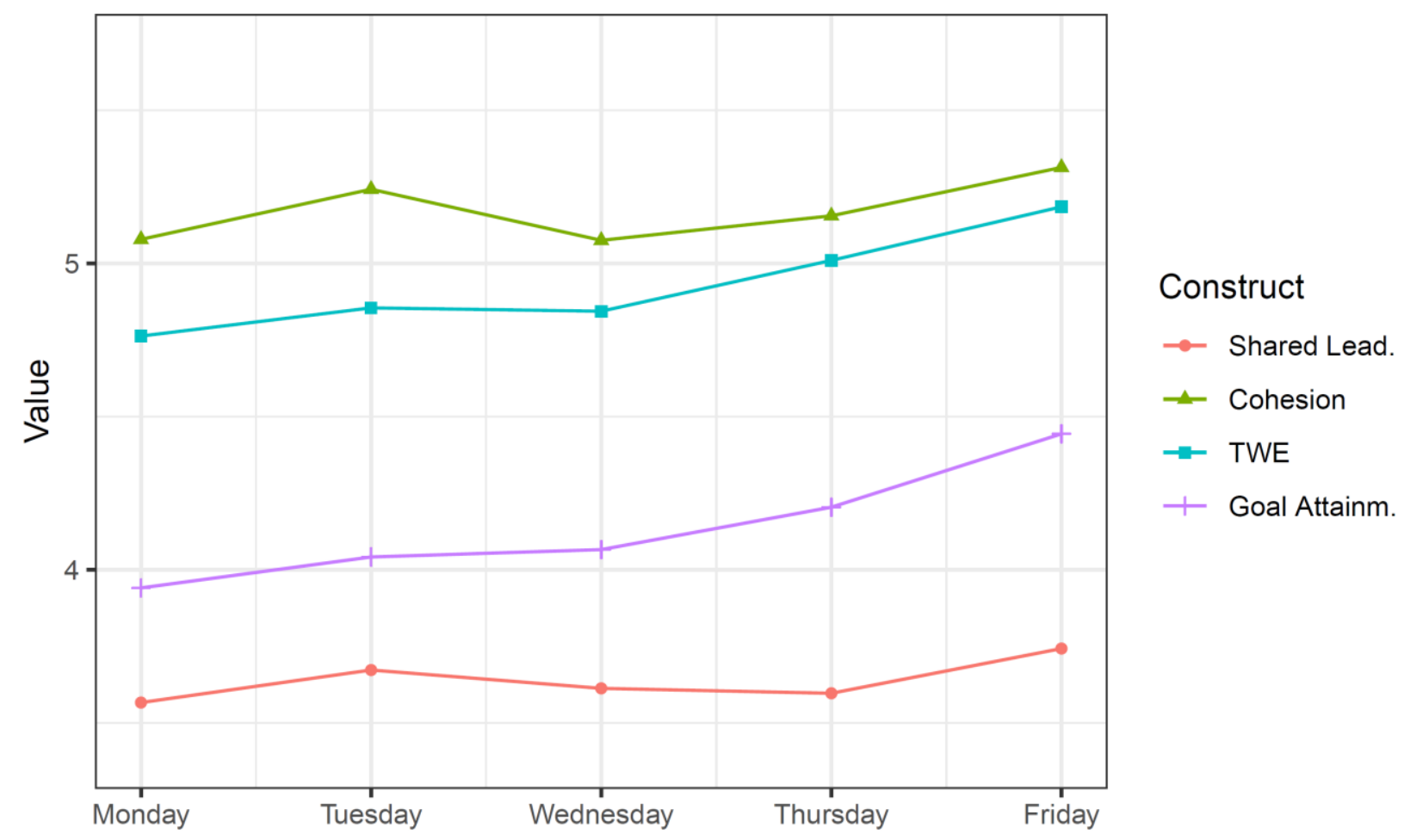

Figure 1. Day-specific values of the constructs aggregated across all teams. TWE $=$ Team work engagement. 


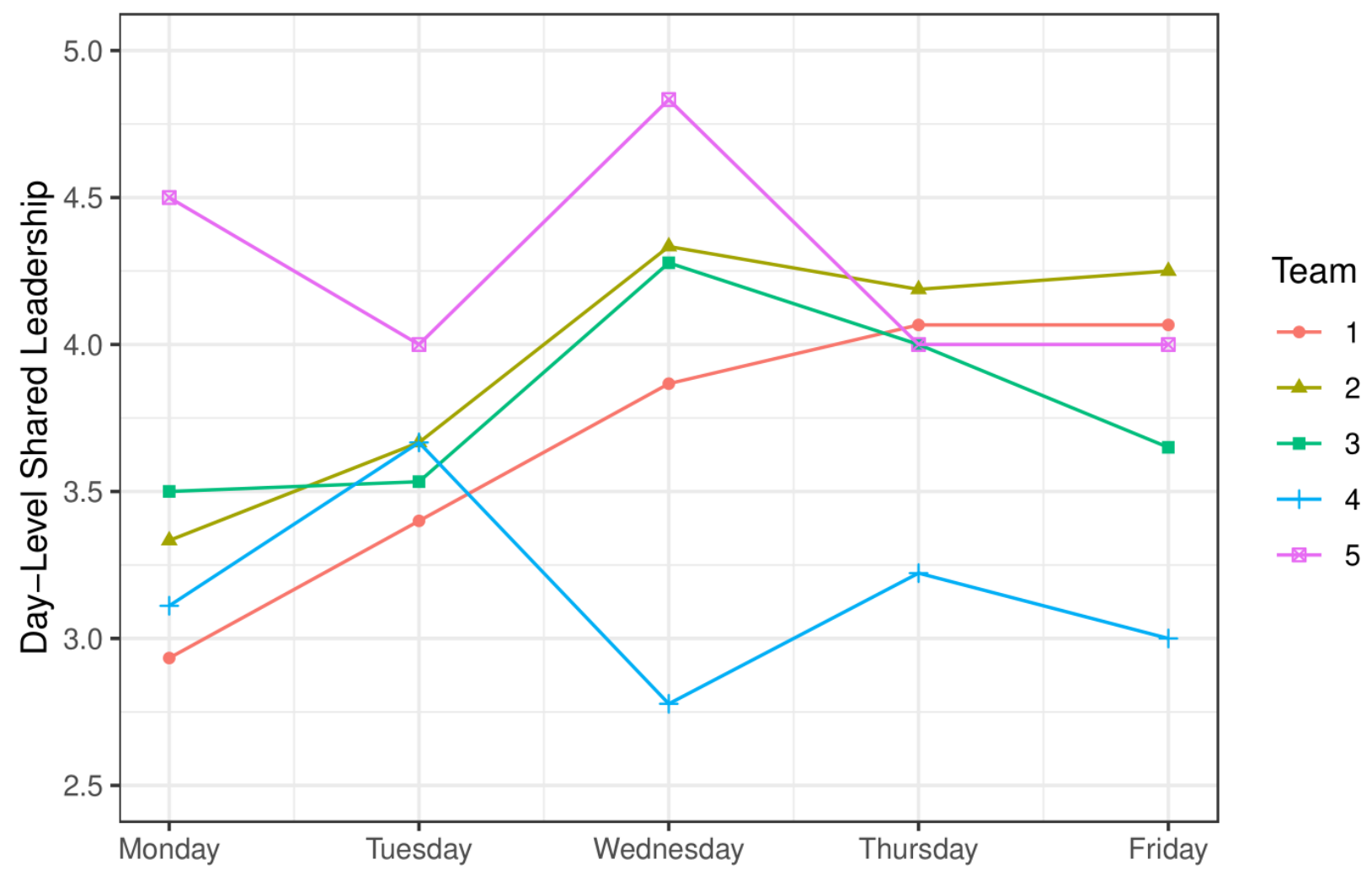

Figure 2. Day-specific values of shared leadership for five different teams. 
Team-Level

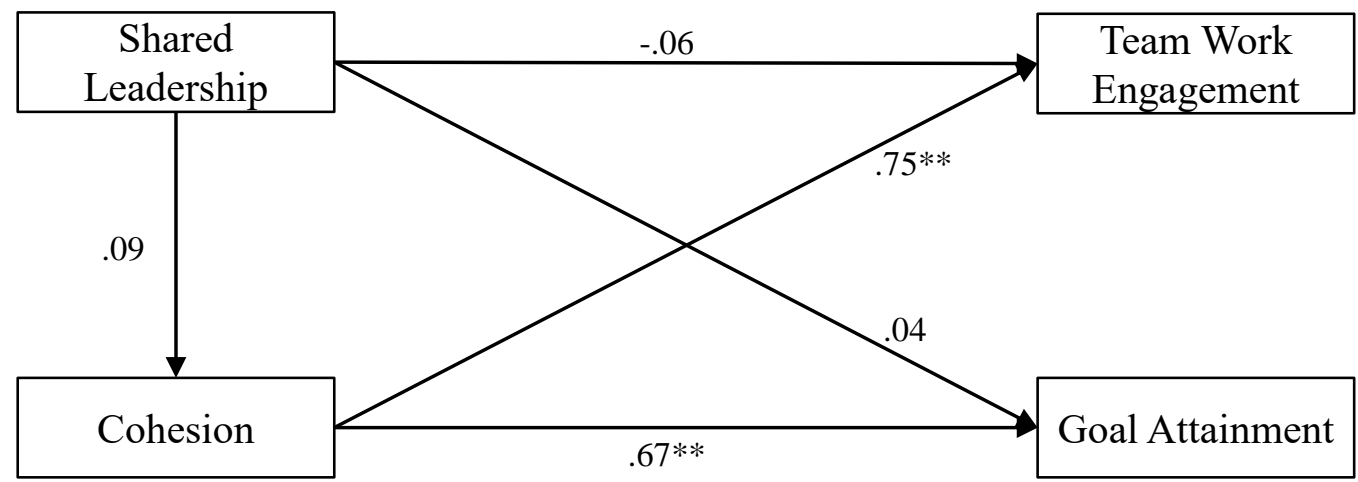

Daily Team-Level

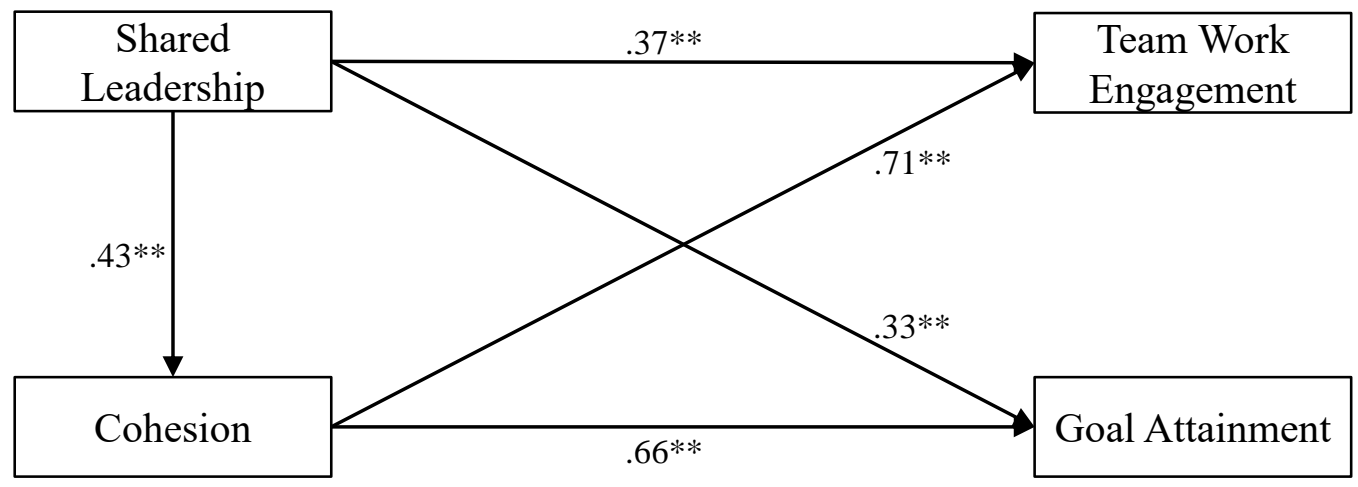

Figure 3. Results from three-level Bayesian path analytic model. Presented are standardized coefficients. The daily person-level results and the covariance between team work engagement and goal attainment are not shown for parsimony.

* 95\%-CI of the posterior distribution excludes zero

$* * 99 \%-\mathrm{CI}$ of the posterior distribution excludes zero 


\section{Online Supplement:}

A diary study on shared leadership, team work engagement, and goal attainment

Team-Level

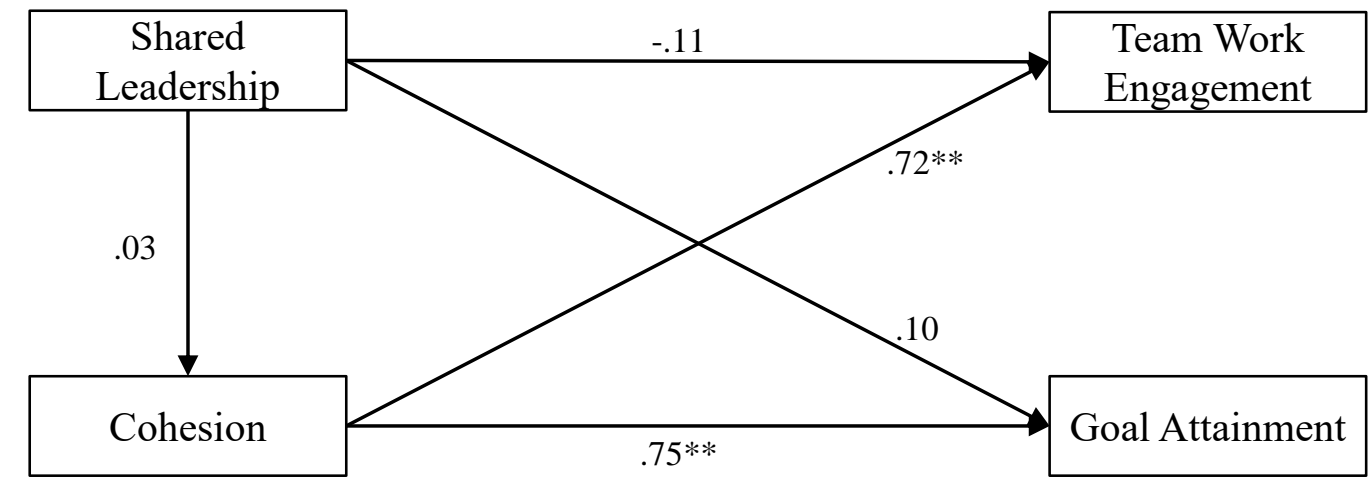

Daily Team-Level

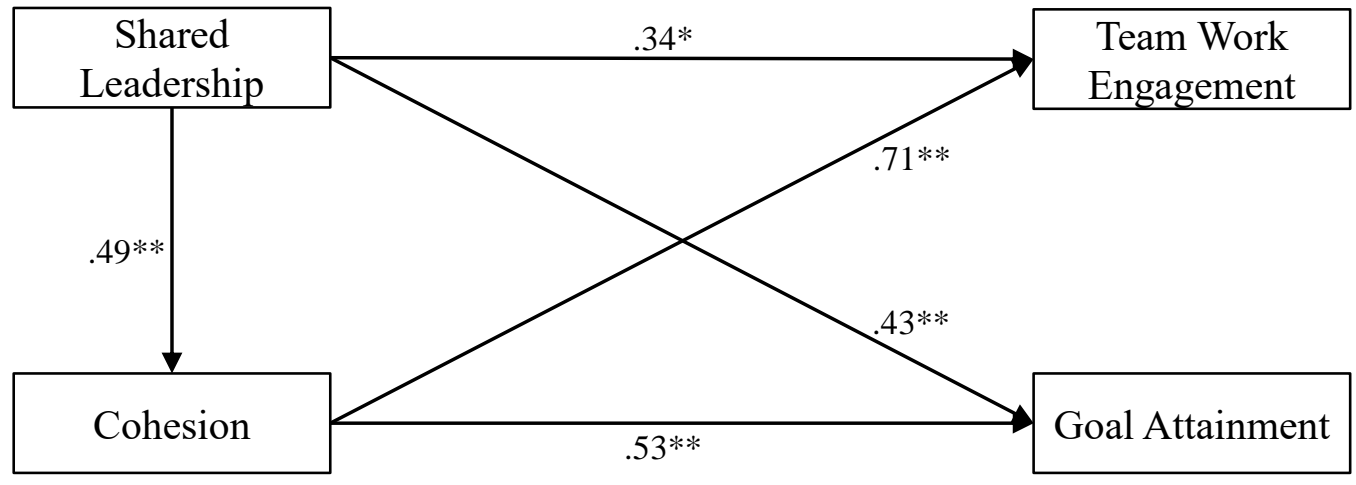

Figure S1. Results from three-level Bayesian path analytic model with complete teams.

Presented are standardized coefficients. The daily person-level results and the covariance between team work engagement and goal attainment are not shown for parsimony.

* 95\%-CI of the posterior distribution excludes zero

** 99\%-CI of the posterior distribution excludes zero 
Team-Level

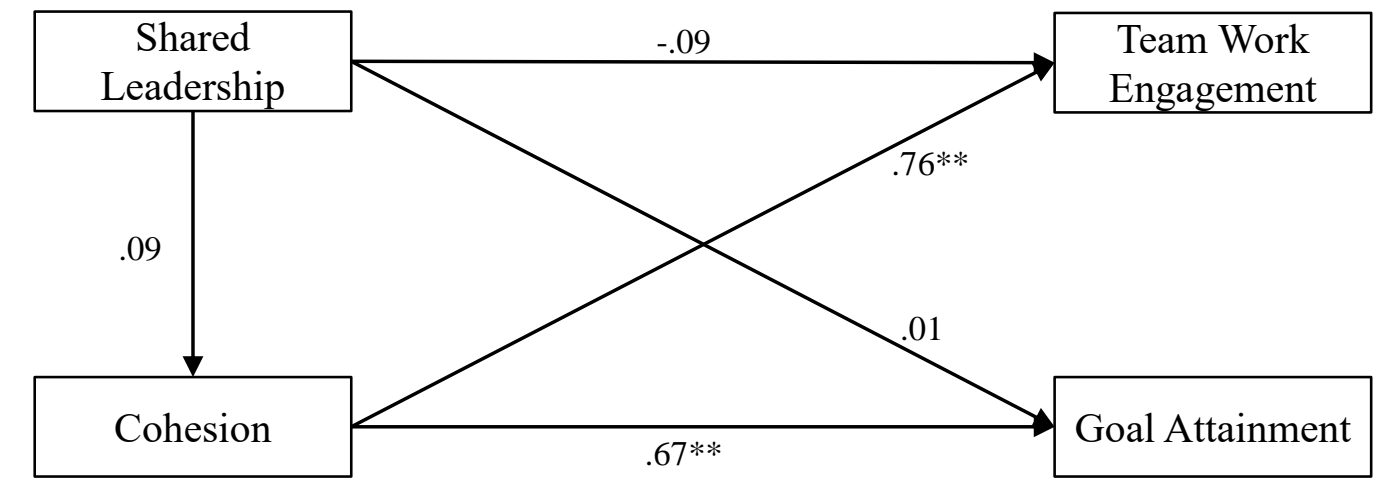

Daily Team-Level

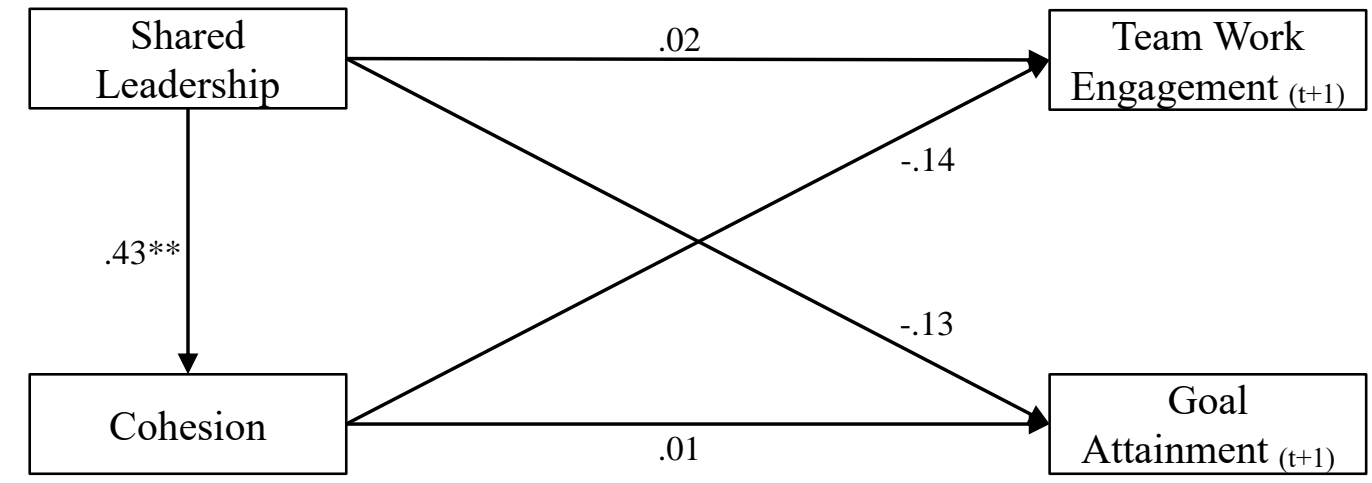

Figure S2. Results from three-level Bayesian path analytic model for time-lagged relationships with next-day team work engagement and goal attainment. Presented are standardized coefficients. The daily person-level results and the covariance between team work engagement and goal attainment are not shown for parsimony.

* 95\%-CI of the posterior distribution excludes zero

** $99 \%-\mathrm{CI}$ of the posterior distribution excludes zero 